\title{
Plant geographic phenotypic variation drives diversification in its associated community of a phytophagous insect and its parasitoids
}

Hui Yu ${ }^{1 *}$ (D, Dan Liang ${ }^{1}$, Enwei Tian ${ }^{1}$, Linna Zheng ${ }^{1}$ and Finn Kjellberg ${ }^{2}$

\begin{abstract}
Background: While the communities constituted by phytophageous insects and their parasites may represent half of all terrestrial animal species, understanding their diversification remains a major challenge. A neglected idea is that geographic phenotypic variation in a host plant may lead to heterogeneous evolutionary responses of the different members of the associated communities. This could result in diversification on a host plant by ecological speciation in some species, leading to geographic variation in community composition. In this study we investigated geographic variation of inflorescence receptacle size in a plant, Ficus hirta, and how the hymenopteran community feeding in the inflorescences has responded. Our predictions were:

1) Inflorescence size variation affects wasp species differently depending on how they access oviposition sites.

2) In some affected lineages of wasps, we may observe vicariant, parapatric species adapted to different inflorescence sizes.
\end{abstract}

Results: We show that fig (the enclosed inflorescence of Ficus) wall thickness varies geographically. The fig-entering pollinating wasp was not affected, while the parasites ovipositing through the fig wall were. Two parapatric species of Philotrypesis, exhibiting strikingly different ovipositor lengths, were recorded. One species of Sycoscapter was also present, and it was restricted, like the shorter-ovipositor Philotrypesis, to the geographic zone where fig walls were thinner.

Conclusions: Previous work on fig wasps suggested that parapatric geographic ranges among congenerics were due to adaptation to variation in abiotic factors, complemented by interspecific competition. Our results show that parapatric ranges may also result from adaptation to variation in biotic factors. Within an insect community, differences among species in their response to geographic phenotypic variation of their host plant may result in geographically heterogeneous community structure. Such heterogeneity leads to heterogeneous interaction networks among sites. Our results support the hypothesis that plant geographic phenotypic variation can be a driver of diversification in associated insect communities, and can complement other diversification processes.

Keywords: Community, Diversification, Co-evolution, Ficus hirta, Fig wasp, Ovipositor length

\footnotetext{
*Correspondence: yuhui@scib.ac.cn

'Guangdong Provincial Key Laboratory of Applied Botany, and Key

Laboratory of Plant Resources Conservation and Sustainable Utilization,

South China Botanical Garden, the Chinese Academy of Sciences,

Guangzhou 510650, China

Full list of author information is available at the end of the article
}

(c) The Author(s). 2018 Open Access This article is distributed under the terms of the Creative Commons Attribution 4.0 International License (http://creativecommons.org/licenses/by/4.0/), which permits unrestricted use, distribution, and reproduction in any medium, provided you give appropriate credit to the original author(s) and the source, provide a link to the Creative Commons license, and indicate if changes were made. The Creative Commons Public Domain Dedication waiver (http://creativecommons.org/publicdomain/zero/1.0/) applies to the data made available in this article, unless otherwise stated. 


\section{Background}

Since the early 1980's the quest for understanding diversification in the communities of phytophages and their parasites associated with plants, has largely focused on the consequences of the colonisation of a new host by an insect phytophage or a parasitoid and the resulting specialisation process [1]. Such host shifts often lead to the formation of host-races and may trigger a cascade of diversification as parasites and hyper-parasites may follow their phytophagous host. Alternatively, parallel diversification of plant host and their associated parasites may occur. In this process, host plant separation into distinct lineages correlates with associated parasite separation into distinct lineages $[2,3]$. Hence there has been an emphasis on exploring the respective roles of parallel diversification versus host shifts in patterns of community diversification [4-7].

An important facet of diversity is represented by geographic variation in its associated communities across the range of a host plant. Widely-distributed plants are likely to be growing in areas with a wide range of environmental conditions, which will vary in suitability for their associated insects. Therefore, large host plant ranges allow the establishment of parapatric vicariant associated insect species, adapted to different environmental conditions [8-10]. In this process, diversification is a response to geographic variation in abiotic factors such as minimum and maximum temperatures [11].

Geographic variation in biotic factors may also strongly affect the interactions between members of the associated communities. If we focus on variation in biological traits of the plants and their associated community member species, then two major processes may be involved. Traits of the interacting species may evolve in direct response to each other, in a co-evolutionary process. However, there is limited support for an important role of coevolutionary diversification in the diversification of life [2,3]. Alternatively, phenotypic variation in one species may be driven by factors extrinsic to the interaction, but nonetheless result in divergent selection on associated species. Classical examples of structured phenotypic variation in plants are geographic variation in plant phenology [12] and geographic variation in the size of particular plant organs [13]. Such variation in plant traits is either a direct plastic phenotypic response to local conditions or the product of local adaptation. Nevertheless, it may have a strong impact on phytophages and their parasites.

Ficus and fig wasps provide a model system to investigate geographic variation in associated community composition. Indeed, Ficus species in general have exceptionally large geographical distributions for tropical trees [14], a feature that facilitates the investigation of geographic variation. Furthermore, sampling whole communities of fig-wasps and assessing specificity is straight-forward. Ficus are characterised by their urn-shaped inflorescence called a fig, the inside of which is lined by female flowers (Fig. 1). A female flower may become a seed, or be transformed into a gall by the mutualistic pollinators or by galling wasps. The galls may in turn be attacked by cleptoparasites or parasitoids. Each galled flower finally produces one adult wasp offspring [15]. The communities of non-pollinating fig wasps on different continents or on different subgenera of Ficus exhibit strikingly different phylogenetic relationships, yet they have similar functional organization, demonstrating convergent evolution of community structure [15].

Pollinating wasps enter the fig cavity through an ostiole and oviposit into ovules by inserting their ovipositor through flower styles, whereas most parasites oviposit through the fig wall (Fig. 1). Hence ostiole and style modifications affect pollinators while fig wall modifications affect parasites [16]. This provides for a decoupling of constraints on pollinators and parasites and, hence, a system in which decoupling of diversification processes can be investigated. Furthermore, Ficus display great intraspecific variation in fig size within species [17]. In some Ficus species, this variation is spatially structured [18].

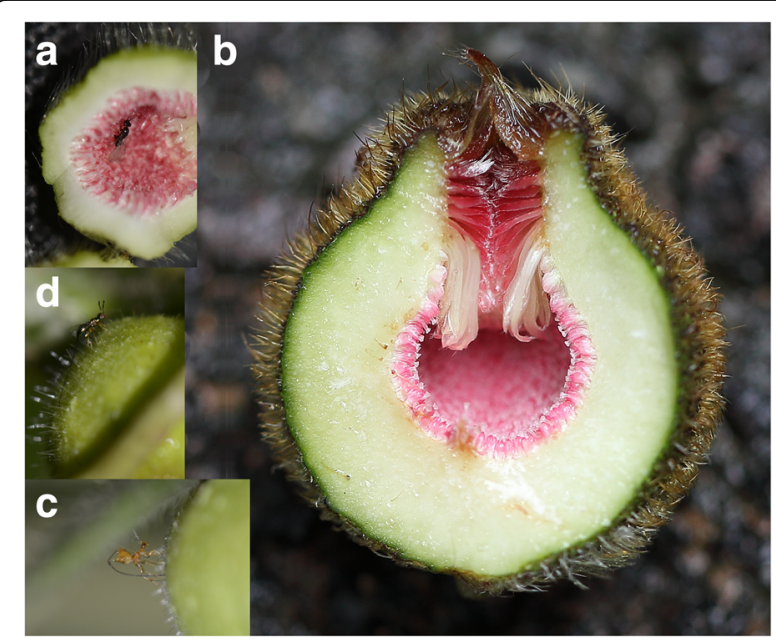

Fig. 1 Geographic variation in fig wall thickness and wasp oviposition. a A Ficus hirta fig from Guangzhou in the south-western part of the study region. A pollinating wasp has entered the fig cavity and is ovipositing into the flowers that line the fig cavity. b A Ficus hirta fig from Fujian province, in the north-eastern part of the range of the species. Note the larger size of the fig and the thicker fig wall. c An ovipositing Philotrypesis. The wasp inserts its ovipositor through the fig wall and will only lay an egg if it reaches an ovule colonised by a pollinator larva. $\mathbf{d}$ An ovipositing Sycoscapter hirticola. The wasp inserts its ovipositor through the fig wall and will only lay an egg if it reaches an ovule colonised by a pollinator larva. The thick fig walls in the northern eastern part of the range of Ficus hirta represent an evolutionary challenge for the parasitic wasp species which oviposit through the fig wall but not for the pollinator which enters the fig 
Here we document, in Ficus hirta, geographic variation in fig morphology in South-East China and a correlated difference in the composition of its associated parasitic fig-wasp community. This variation occurs within a context of strong gene flow and a lack of genetic isolation by distance, in both Ficus hirta and its pollinating wasp Valisia hilli, throughout the region [9].

\section{Methods}

\section{Natural history of system}

Ficus hirta Vahl is a tropical to subtropical shrub of secondary vegetation. In South-East China it is pollinated by Valisia hilli Wiebes (Agaonidae, Chalcidoidea). Ficus hirta is a functionally dioecious species. In female plants, flower ovules produce seeds and no wasps, while in functionally male plants, flower ovules host wasp larvae and do not produce seeds. During sampling we observed two parasitic fig wasps, Philotrypesis josephi and Sycoscapter hirticola (Sycoryctinae, Pteromalidae, Chalcidoidea) [19]. Both species oviposit from outside the fig into ovaries by inserting their long ovipositor through the fig wall (Fig. 1). Wasps of the genus Philotrypesis are assumed to be cleptoparasites, each larva replacing a pollinator larva and feeding on gall tissue. Wasps of the genus Sycoscapter are assumed to be parasitoids, each larva feeding on one pollinator larva [20]. Philotrypesis josephi and Sycoscapter hirticola oviposit in figs that have been recently visited by pollinators ( $\mathrm{Yu}$, unpublished observations).

\section{Sites and sample collection}

Between June 2006 and July 2013, we sampled wasps for genetic analysis from 11 sites on the mainland of South East China and 2 sites in Hainan island (Fig. 2; Table 1) spanning a distance of over $1000 \mathrm{~km}$, and reaching the north-eastern limit of the range of $F$. hirta. Figs and parasitic wasps were collected for morphological assessment from 8 sites. Philotrypesis wasps were present in all sites while Sycoscapter wasps were absent from the northeastern sites. Hence, for Sycoscapter, we obtained samples for genetic analysis from 7 sites on the mainland of South

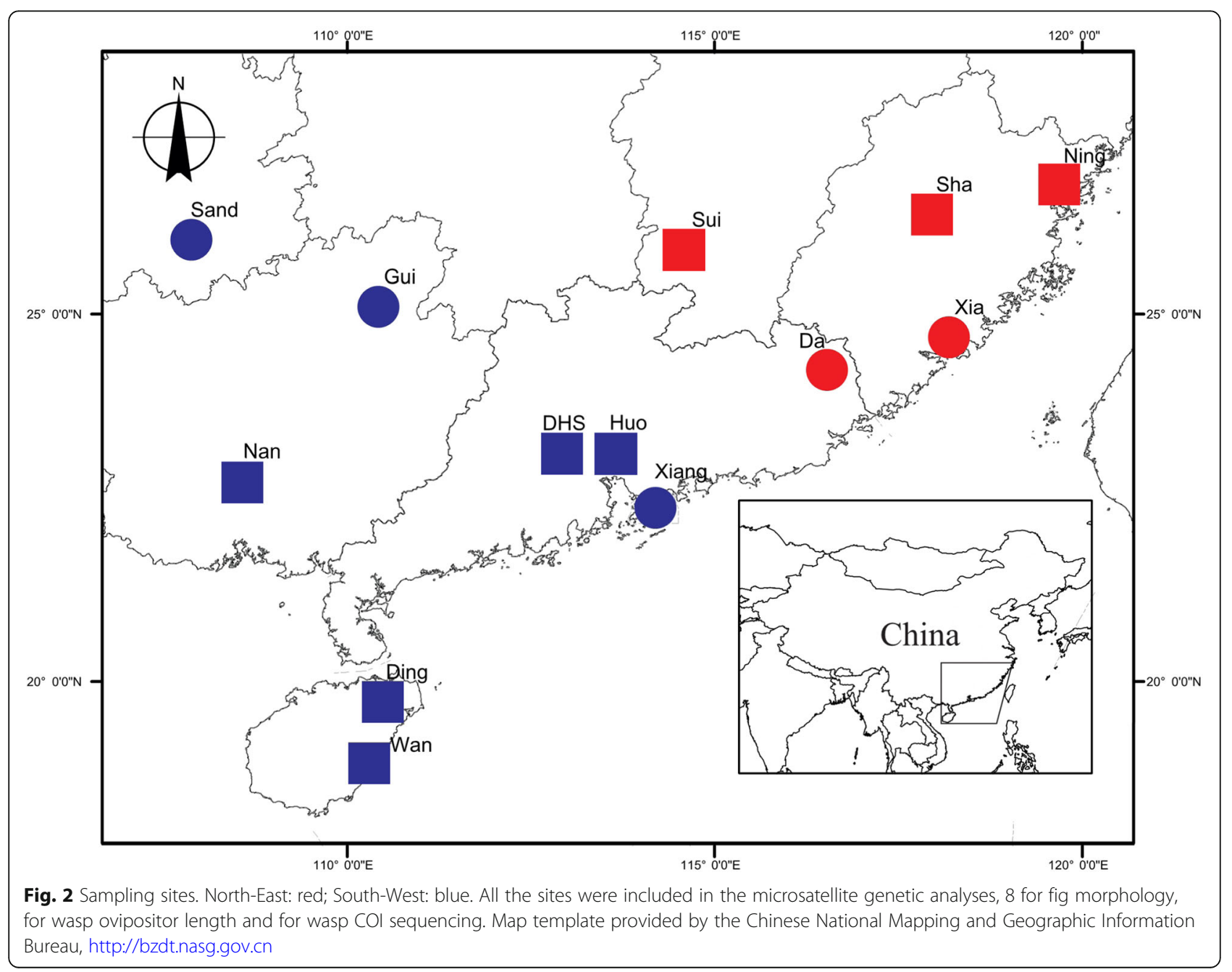


Table 1 Sampling sites and sample sizes for microsatellite analysis

\begin{tabular}{llll}
\hline Site & Latitude, Longitude & Philotrypesis & Sycoscapter \\
\hline Ning & $26^{\circ} 39^{\prime} 51^{\prime \prime} \mathrm{N}, 119^{\circ} 32^{\prime} 56^{\prime \prime} \mathrm{E}$ & 25 & - \\
Sha & $26^{\circ} 23^{\prime} 50^{\prime \prime} \mathrm{N}, 117^{\circ} 47^{\prime} 32^{\prime \prime} \mathrm{E}$ & 20 & - \\
Xia & $24^{\circ} 44^{\prime} 33^{\prime \prime} \mathrm{N}, 118^{\circ} 4^{\prime} 20^{\prime \prime} \mathrm{E}$ & 11 & - \\
Sui & $25^{\circ} 45^{\prime} 09^{\prime \prime} \mathrm{N}, 114^{\circ} 16^{\prime} 58^{\prime \prime} \mathrm{E}$ & 24 & - \\
Da & $24^{\circ} 15^{\prime} 30^{\prime \prime} \mathrm{N}, 116^{\circ} 48^{\prime} 22^{\prime \prime} \mathrm{E}$ & 15 & - \\
Gui & $25^{\circ} 04^{\prime} 36^{\prime \prime} \mathrm{N}, 110^{\circ} 18^{\prime} 21^{\prime \prime} \mathrm{E}$ & 12 & 8 \\
Huo & $23^{\circ} 11^{\prime} 11^{\prime \prime} \mathrm{N}, 113^{\circ} 21^{\prime} 56^{\prime \prime} \mathrm{E}$ & 15 & 24 \\
DHS & $23^{\circ} 02^{\prime} 49^{\prime \prime} \mathrm{N}, 112^{\circ} 27^{\prime} 54^{\prime \prime} \mathrm{E}$ & 16 & 19 \\
Xiang & $22^{\circ} 23^{\prime} 47^{\prime \prime} \mathrm{N}, 114^{\circ} 06^{\prime} 34^{\prime \prime} \mathrm{E}$ & 21 & 21 \\
Sand & $25^{\circ} 59^{\prime} 08^{\prime \prime} \mathrm{N}, 107^{\circ} 52^{\prime} 28^{\prime \prime} \mathrm{E}$ & 12 & 21 \\
Nan & $22^{\circ} 49^{\prime} 03^{\prime \prime} \mathrm{N}, 108^{\circ} 21^{\prime} 56^{\prime \prime} \mathrm{E}$ & 20 & 9 \\
Ding & $19^{\circ} 41^{\prime} 50^{\prime \prime} \mathrm{N}, 110^{\circ} 19^{\prime} 42^{\prime \prime} \mathrm{E}$ & 24 & 24 \\
Wan & $18^{\circ} 47^{\prime} 42^{\prime \prime} \mathrm{N}, 110^{\circ} 23^{\prime} 27^{\prime \prime} \mathrm{E}$ & 17 & 17 \\
Total & & 207 & 148 \\
\hline
\end{tabular}

East China and 2 sites in Hainan Island, and morphological analysis was carried out for 5 sites.

\section{Fig size variation and ovipositor length of Philotrypesis and}

\section{Sycoscapter}

Figs on male trees were collected in January 2015, at the stage at which the parasitic wasps oviposit (the early phase after pollinator oviposition, when the fig cavity is filled up by flowers transformed into galls, each containing a wasp larva). The length and the diameter of figs and the thickness of the fig wall were measured using readings of a Vernier caliper to the nearest hundredth of a millimeter. Wasps were collected following Tian et al. [9]. Wasps preserved in $70 \%$ ethanol were dissected to reveal the entire length of the ovipositor and measured under a dissection microscope to the nearest $0.01 \mathrm{~mm}$ using a measuring eyepiece. Body length was measured excluding the modified terminal tergites which cover the sheath of the ovipositor.

Size measurements were analyzed using linear models as implemented in R3.3.2 with the package lmtest [21]. The correlations between fig diameter and thickness of the fig wall on one hand, and wasp size, and ovipositor length on the other hand were analyzed using multiple linear regressions comparing north-eastern versus south-western regional effects and individual site effects.

\section{Species discrimination using sequence data and population genetics}

In each site, 10 to 30 mature figs were collected just before wasp emergence. The figs were placed in fine-mesh bags to allow the wasps to emerge naturally. The wasps that emerged were preserved in 95\% ethanol and stored at $-20{ }^{\circ} \mathrm{C}$ until deoxyribonucleic acid (DNA) extraction. For each species, a single female wasp per fig was used for genetic analyses. Sample sizes are given in Table 1.

To delimit species, we sequenced the cytochrome c oxidase subunit I (COI) gene on a number of individuals of Philotrypesis and Sycoscapter from every site for which wasp measurements were made, representing a total of 70 individuals from 8 sites for Philotrypesis and 73 individuals from 5 sites for Sycoscapter. Seven published Philotrypesis COI sequences, 3 from Hainan Island and 4 from Fujian were also included in the analysis [22, 23]. We built COI neighbor joining trees for the two genera. Putative species were delimited as clearly defined monophyletic clades in neighbour joining trees. Genetic separation between putative species was visualized by plotting Kimura 2-parameter pairwise genetic distances (K2P) [24] within species and between species. For the purpose of comparison, we plotted the distribution of $\mathrm{K} 2 \mathrm{P}$ pairwise distances for the pollinating wasps using previously published data for the same region [9]. To provide a background framework, we analyzed the fine grained spatial genetic structure within $F$. hirta, by plotting genetic differentiation between populations $\left(F_{S T} / 1-F_{S T}\right)$ (F-statistics describe the statistically expected level of heterozygosity in a population, and $F_{S T}$ is the effect of subpopulations compared to the total population) according to distance using previously published microsatellite genotype data [25].

Genomic DNA was extracted from the whole body of each female fig wasp using the EasyPure Genomic DNA Extraction Kit (TransGen, Beijing, China). A 545 bp fragment of the COI gene of Philotrypesis and 560 bp fragment of the COI gene of Sycoscapter was amplified using the universal primer pair (LCO1490: 5'-GGTCAACAA ATCATAAAGATATTGG-3', HCO2198: 5' - TAAA CTTCAGGGTGACCAAAAAATCA -3') [26]. PCR amplification of COI was carried out in a $20 \mu \mathrm{l}$ volume using $10 \times$ buffer, $2 \mathrm{mM} \mathrm{Mg}{ }^{2+}, 0.25 \mathrm{mM}$ each dNTP, primer 0.6 $\mathrm{uM}$, Taq polymerase (Takara) $2 \mathrm{U}$ and DNA $150 \mathrm{ng}$. The reaction was optimized and programmed on a MJ Thermal Cycler (PTC 200) as one cycle of denaturation at $94^{\circ}$ $\mathrm{C}$ for $3 \mathrm{~min}, 35$ cycles of $30 \mathrm{~s}$ denaturation at $92{ }^{\circ} \mathrm{C}, 30 \mathrm{~s}$ at a $48{ }^{\circ} \mathrm{C}$ annealing temperature, and $30 \mathrm{~s}$ extension at $72{ }^{\circ} \mathrm{C}$, followed by $10 \mathrm{~min}$ extension at $72{ }^{\circ} \mathrm{C}$. All amplified PCR products were purified using QIAquick spin columns (Qiagen) and were sequenced in an ABI 3730xl capillary sequencer using BigDye Terminator V 3.1 chemistry (Applied Biosystems). Consensus sequences were aligned using MUSCLE implemented in MEGA 6.0 [27] with manual corrections. Haplotype sequences have been deposited in GenBank under Accession No: MG548662-700 and MG548701-24.

We used a neighbour-joining tree (NJ tree) to reconstruct the phylogenetic relationships based on all COI 
sequences of Philotrypesis and Sycoscapter. NJ was reconstructed using MEGA 6.0 [27] and node supports were assessed based on 1000 bootstrap replicates. For Philotrypesis, we also include Philotrypesis anguliceps hosted by Ficus religiosa (JQ408678), Philotrypesis sp1 hosted by Ficus oligodon (JN545271), and two haplotypes of Philotrypesis spinipes hosted by Ficus fistulosa (JQ408674, JQ408677) [22, 23] as the outgroup. For Sycoscapter, we use three Philotrypesis sequences (one from the south-western species and two from the north-eastern species) generated in the current study as outgroups because of a lack of COI sequences of the family in Genbank. K2P pairwise distances were calculated within species and between putative congeneric species.

In a second step, individuals from all sampling sites were genotyped at microsatellite loci and Bayesian clustering was used to determine the optimal number of groups using STRUCTURE 2.3.4 [28] and STRUCTURE HARVESTER [29]. Assignation of individuals within sites to clusters was compared with the geographic distribution of putative species according to COI genotyping, to detect potential local co-occurrence of species.

Pairwise $F_{S T}$ values of genetic differentiation among populations were calculated and the values compared using SPAGeDI1.5 [30]. Significance of spatial genetic structure was evaluated with 20,000 permutations.

For Philotrypesis, two hundred and seven individuals were genotyped at 6 unlinked microsatellite loci (P50, P86, P91, P123, P129 and P202) that had been previously developed for the species [31], and for Sycoscapter hirticola, one hundred and fourty-eight individuals were genotyped at 7 unlinked microsatellite loci (S7, S27, S52, S122, S132, S137 and S162) that had been previously developed for the species [32]. Molecular analysis techniques followed Abellò et al. [31] for P. josephi and Ahanchédé et al. [32] for S. hirticola.
The methods for PCR amplification and analysis of microsatellites were identical between Sycoscapter and Philotrypesis excep

$\mathrm{t}$ for the annealing temperature. The amplification reactions were conducted using a PTC-200 thermal cycler (Bio-Rad, Hercules, CA) in $20 \mu \mathrm{l}$ volume containing $20 \mathrm{ng}$ of genomic DNA, $0.2 \mathrm{mM}$ of each dNTP, $0.4 \mu \mathrm{M}$ of fluorescent primer, 1 ul of $10 \times$ PCR buffer $\left(\mathrm{Mg}^{2+}\right.$ free), $2.5 \mathrm{mM} \mathrm{Mg}^{2+}$ and 1 unit of Taq DNA polymerase (Takara, Dalian, China), using the following conditions: initial denaturation at $95{ }^{\circ} \mathrm{C}$ for $5 \mathrm{~min}, 35$ cycles of $\left(94{ }^{\circ} \mathrm{C}, 30 \mathrm{~s} ; 46\right.$ to $50{ }^{\circ} \mathrm{C}, 60 \mathrm{~s}$ for Sycoscapter and $72{ }^{\circ} \mathrm{C}, 45 \mathrm{~s} ; 47$ to $52{ }^{\circ} \mathrm{C}$, $60 \mathrm{~s}$ for Philotrypesis) and a final extension of $72{ }^{\circ} \mathrm{C}$ for 8 min (see Table 1 for annealing temperatures of each primer pair). The fragment sizes of the PCR products were determined on the ABI PRISM 3100 Genetic Analyser (Applied Biosystems, Foster City, CA) using genotyper 4.0 and LIZ 500 (Applied Biosystems, Foster City, CA) as an internal size standard.

\section{Results}

Fig wall thickness varied geographically and was correlated with the presence and morphology of the parasitic wasps. Ficus hirta individuals from north-eastern sites produced figs with thicker walls than individuals from south-western sites $\left(\mathrm{F}_{1,288}=970, p<10^{-93}\right)$. The difference was mainly due to the production of larger diameter figs, which exhibited thicker fig walls (Fig. 1; Fig. 3; Table 2). Indeed, the correlation of fig wall thickness with fig size explained $70 \%$ of the variance in fig-wall thickness $\left(\mathrm{F}_{1,288}=1031, p<10^{-96}\right)$. A north east-south west difference in the correlation was also detected, but explained only $8.8 \%$ of the variance $\left(\mathrm{F}_{1,288}=127, p<10^{-24}\right)$.

Philotrypesis wasps and Sycoscapter wasps exhibited similar ovipositor length at south-western sites, with a mean value per site of $3.12-3.31 \mathrm{~mm}$ for Philotrypesis and 3.21-3.55 $\mathrm{mm}$ for Sycoscapter (Fig. 3; Table 2). In
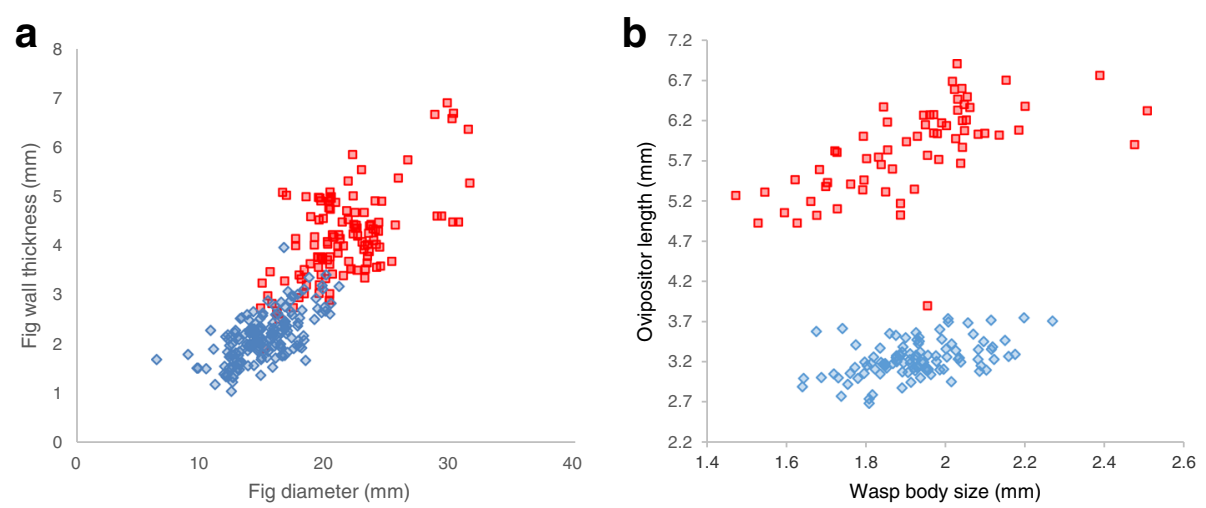

Fig. 3 Fig size, fig wall thickness and Philotrypesis ovipositor length. a Figs from north-eastern sites (red squares), are large and as a consequence have thicker fig walls than figs from south-western sites (blue diamonds). $\mathbf{b}$ While wasps from south-western sites (blue) and the wasps from north-eastern sites (red) exhibit identical body lengths, they differ strongly in the relationship between body size and ovipositor length 
Table 2 Fig and wasp morphology according to sampling site

\begin{tabular}{|c|c|c|c|c|c|c|c|}
\hline \multirow[b]{2}{*}{ Site } & \multicolumn{3}{|l|}{ Fig } & \multicolumn{2}{|c|}{ Philotrypesis } & \multicolumn{2}{|l|}{ Sycoscapter } \\
\hline & $\begin{array}{l}\text { figs } \\
\text { /plants }\end{array}$ & Fig diameter (mm) & Thickness of fig wall (mm) & wasps & Ovipositor length (mm) & wasps/figs & Ovipositor length (mm) \\
\hline \multicolumn{8}{|c|}{ Northern sites } \\
\hline Ning & $36 / 9$ & $23.23 \pm 4.87$ & $4.91 \pm 0.89$ & $24 / 10$ & $5.99 \pm 0.42$ & 0/0 & \\
\hline Sha & $43 / 14$ & $21.42 \pm 2.62$ & $3.88 \pm 0.59$ & $21 / 6$ & $5.73 \pm 0.32$ & $0 / 0$ & \\
\hline Sui & $42 / 12$ & $19.99 \pm 2.62$ & $3.74 \pm 0.79$ & $23 / 5$ & $5.31 \pm 0.43$ & $0 / 0$ & \\
\hline \multicolumn{8}{|c|}{ Southern sites } \\
\hline Huo & $42 / 21$ & $14.32 \pm 2.75$ & $1.92 \pm 0.40$ & $21 / 3$ & $3.31 \pm 0.23$ & $14 / 5$ & $3.55 \pm 0.24$ \\
\hline DHS & $40 / 16$ & $13.39 \pm 1.72$ & $2.10 \pm 0.34$ & $21 / 8$ & $3.24 \pm 0.24$ & $13 / 7$ & $3.52 \pm 0.23$ \\
\hline Nan & $41 / 13$ & $16.76 \pm 2.04$ & $2.38 \pm 0.43$ & $21 / 6$ & $3.43 \pm 0.23$ & $11 / 5$ & $3.23 \pm 0.13$ \\
\hline Ding & $14 / 9$ & $15.47 \pm 1.64$ & $2.34 \pm 0.36$ & $21 / 4$ & $3.12 \pm 0.12$ & $4 / 2$ & $3.21 \pm 0.19$ \\
\hline Wan & $33 / 11$ & $15.32 \pm 2.26$ & $2.12 \pm 0.70$ & $20 / 4$ & $3.16 \pm 0.15$ & $11 / 2$ & $3.25 \pm 0.13$ \\
\hline
\end{tabular}

the north-east, Sycoscapter was totally absent, while Philotrypesis wasps exhibited much longer ovipositors, three times as long as body length (Fig. 3; mean value per site: 5.31-5.99 mm, Table 2). At all sites, the average length of parasite ovipositors was larger than the average thickness of fig wall, allowing oviposition to take place (Table 2). Ovipositors of wasps from south-western sites were all shorter than fig-wall thicknesses in north-eastern sites, preventing reproduction of potential south-north migrants (Table 2). While Philotrypesis wasps in north-eastern sites exhibited much longer ovipositors than in south-western sites $\left(\mathrm{F}_{1,167}=1824, p<10^{-90}\right)$, wasp body size was not larger (Fig. 3, $F_{1,167}=0.0086, p=0.93$ ). The difference resulted from a major difference in mean value of ovipositor length, which explained $90 \%$ of the variance, and to a lesser extent from a difference in the slope of the correlation between body length and ovipositor length. Although ovipositor length was correlated with wasp length in both Philotrypesis wasps and Sycoscapter wasps, for Philotrypesis wasps the slope of the correlation was steeper among north-eastern wasps than south-western wasps (Fig. 3, $\mathrm{F}_{1,165}=7.97, p=0.005$;).

Philotrypesis wasps also exhibited variation in other body traits. Tibia length and femur length were slightly longer in north-eastern than in south-western wasps (the difference representing respectively 2.5 and $3.7 \%$ of the variance, $p<0.05$ ), while the tarsi of north-eastern wasps were markedly longer (Fig. $4 \mathrm{~b}$, representing $14 \%$ of the variance, $F_{1,167}=27.7, p<10^{-6}$;). North-eastern wasps also exhibited disproportionally longer wings (Fig. $4 \mathrm{a}$, the geographic regions representing $10 \%$ of the variance, $\left.F_{1,165}=19.2, p<10^{-4}\right)$. On the other hand head size differed only slightly between north-eastern and south-western wasps (Fig. 4d, explaining 3\% of the variance, $\left.\mathrm{F}_{1,166}=5.05, p<0.05\right)$. Hence, the difference in ovipositor allometry correlated with differences in the allometries of a series of traits such as wing length and tarsus length. Site effects within region were generally significant, but explained much less of the variance than the binary geographic effect.

Putative species were delimited as clearly defined monophyletic clades in neighbour joining trees based on COI data. Haplotype differentiation was limited in Sycoscapter, suggesting the presence of a single species (Additional file 1: Figure S1). This result was confirmed by a unimodal distribution of K2P distances between individuals (Fig. 5). Haplotype differentiation was much higher in Philotrypesis, clearly separating the two putative species (Additional file 1: Figure S2). All sequenced individuals from short ovipositor populations belonged to one putative species and all sequenced individuals originating from long ovipositor populations belonged to the other putative species (100\% branch support). The K2P pairwise distance distribution shows a marked barcoding gap separating within and between putative species pairwise distances (Fig. 5). K2P pairwise distances within the pollinator Valisia hilli were much smaller than for Philotrypesis and Sycoscapter (Fig. 5). The distribution of K2P pairwise distances on the continent was unimodal, with no separation between individuals originating from north-eastern or south-western locations. Finally, in the pollinator, the distribution of K2P pairwise distances between the continent and Hainan Island was displaced towards somewhat higher values, but without a barcoding gap (Fig. 5).

For Sycoscapter, the optimal number of genetic groups following the Evanno criterion [33] was one or two. For $K=2$, STRUCTURE results separated the closely located sites Huo, Xiang and DHS from the other sites, suggesting a geographic effect (Additional file 1: Figure S3a).

Running STRUCTURE with Philotrypesis microsatellite genotypes for $\mathrm{K}=2$ separated individuals into those originating from north-eastern populations and those originating from south-western populations, supporting 

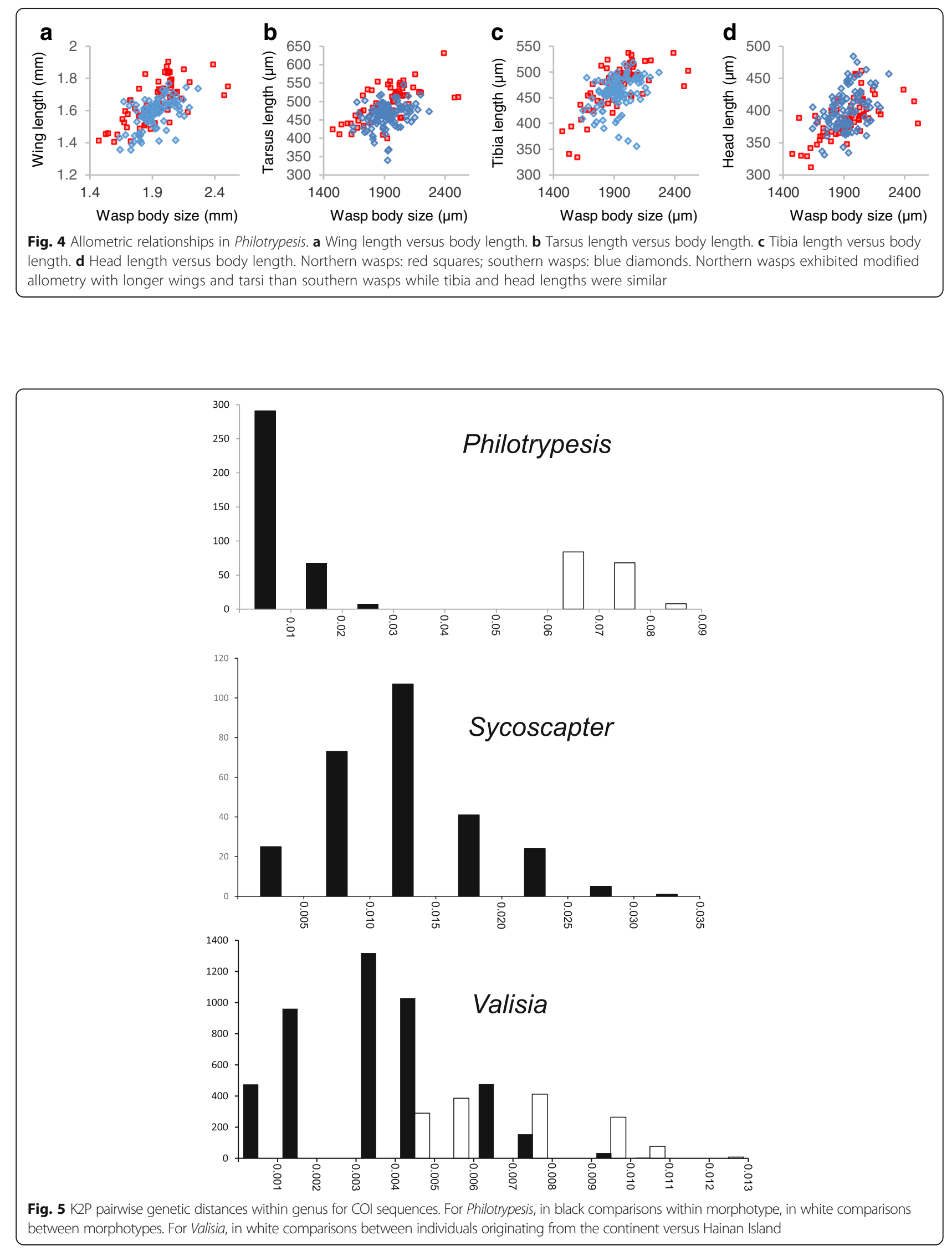
the separation of Philotrypesis into two allopatric putative species (Additional file 1: Figure S3b). According to the Evanno criterion, the optimal value of $\mathrm{K}$ was 4 . One cluster was constituted by the north-eastern species, and the south-western species was distributed into three groups that were not separated by the COI sequences (Additional file 1: Figure S3c).

In the short ovipositor Philotrypesis putative species, there was no genetic isolation by distance and genetic differentiation among sites was high (Additional file 1: Figure S4; global $F_{S T}$ value $=0.22$ ). In the long ovipositor Philotrypesis putative species, genetic differentiation among sites was much more limited ((Additional file 1: Figure S4; global $F_{S T}$ value $=0.034$ ) and there was also no genetic isolation by distance. In the Sycoscapter species, differentiation among sites was intermediate (Additional file 1: Figure S4; global $F_{S T}$ value $=0.13$ ) and there was significant isolation by distance $(p=0.01)$. In both Philotrypesis and Sycophaga, Hainan Island did not show any disproportionately greater genetic differentiation compared to continental populations. In Valisia, there was limited genetic differentiation among continental sites, and the variation was not spatially structured (Additional file 1: Figure S4).

Gene diversity values for microsatellite data suggest that the short ovipositor Philotrypesis putative species is genetically more diverse than the long ovipositor putative species (Nei gene diversity corrected for sample size [34], short $\mathrm{He}=0.84$; long $\mathrm{He}=0.68$; Sycoscapter $\mathrm{He}=0.64$; pollinator $\mathrm{He}=0.67$, recalculated from previously published data).

For F. hirta, genetic differentiation according to distance for continental sites separates a very homogeneous group of sites including all analyzed south-western sites plus site Da. The three other analyzed north-eastern sites are more different, between themselves and comparatively to all other sites, with no effect of geographic distance (Additional file 1: Figure S4).

\section{Discussion}

Our results show that figs of $F$. hirta have thicker walls in north-eastern sites than in south-western ones. In south-western sites we observed one species of Sycoscapter and one species of Philotrypesis. Both species exhibited relatively short ovipositors that could only allow them to oviposit in south-western figs. In north-eastern sites, Sycoscapter was absent and Philotrypesis was represented by a distinct lineage exhibiting long ovipositors that allow it to oviposit into north-eastern figs. In parasitic fig wasps, such differences in ovipositor length are generally observed in comparisons between species ovipositing at markedly different times in fig development and hence in host larval development $[8,15,35]$. To our knowledge, it has never been documented between vicariant lineages on the same host.

Longer ovipositors generate a number of morphological constraints on the wasps. During oviposition of Philotrypesis, the ovipositor shaft is inserted orthogonally to the fig surface (Fig. 1c) and hence, the use of longer ovipositors requires longer legs, as we observed, mainly due to longer tarsi. Further, an ovipositor twice as long as body size is an impediment to flight and this may explain why north-eastern Philotrypesis exhibited longer wings compared to body size.

The ovipositor length of externally-ovipositing non pollinating fig wasps often limits the number of hosts accessible to them. In some cases this is due to variation in fig wall thickness that totally protects some figs against parasites [16]. In other cases those galls containing potential hosts, that are located furthest away from the fig wall are out of the reach of the parasite's ovipositors [36, 37]. This suggests a trade-off between costs and benefits of longer ovipositors. Our results suggest that one of the costs could relate to flight capacity.

In Philotrypesis, the distribution of K2P pairwise distances was bimodal with a marked barcoding gap, suggesting the presence of two distinct species. Results obtained for nuclear microsatellite data using STRUCTURE for $\mathrm{K}=2$ were consistent with a subdivision into two distinct genetic entities. Non ambiguous genetic separation correlating with large morphological difference between the two morphs shows that the two Philotrypesis lineages are distinct species.

Bayesian assignment using STRUCTURE for values higher than 2 allowed separating the short ovipositor Philotrypesis genotypes originating from different sites into different clusters. This structuring among southwestern sites is confirmed by high $F_{S T}$ values and represents genetic differentiation within species, among sites. This differentiation did not follow a pattern of genetic isolation by distance. On the other hand, in Sycoscapter, the assignation to cluster using STRUCTURE followed a geographic proximity pattern, suggesting genetic isolation by distance. This interpretation is further supported by a significant correlation between geographic distance and genetic differentiation between populations, $F_{S T} /$ $\left(1-F_{S T}\right)$. Finally, in Valisia, there was limited, unstructured variation on the continent. However, Valisia wasps from Hainan Island were clearly differentiated [9] while such a differentiation was not observed in Philotrypesis and Sycophaga. Hence the patterns of geographic genetic variation were strikingly different among the four wasp species associated with figs of Ficus hirta. Heterogeneous spatial genetic structure among the different members of the associated wasp community has also been reported for other fig wasps communities [10]. Such differences among members of 
a community may lead to heterogeneous rates of speciation.

The presence of two Philotrypesis species on Ficus hirta could result either from speciation on $F$. hirta or from a host shift, where one of the species originated from another Ficus species. In the study zone, and in China in general, the only close relative of Ficus hirta is Ficus triloba [39]. In our collections of wasps from Ficus triloba we have never observed any Philotrypesis, but we have collected a species of Sycoscapter with a very long ovipositor. This suggests that Philotrypesis has speciated on Ficus hirta, a proposition that needs to be confirmed by a broader phylogenetic study of the Philotrypesis species associated with Ficus section Eriosycea. On the other hand Sycoscapter has failed to colonize north-eastern sites, suggesting limiting adaptive potential.

We may speculate as to which evolutionary process led to speciation in Philotrypesis. A classic scenario would be based on an allopatric diversification process made possible by fragmentation of the range of the associates during climatic oscillations. This would have allowed local (co)evolution in isolation, resulting in differentiated morphs in the plant, and speciation in Philotrypesis. However, almost all available genetic data on Ficus, including Ficus hirta, evidence strong gene flow and limited, if any, genetic structuring for neutral genes across continental ranges [25, 40, 41]. This suggests that genetic differentiation in isolation is infrequent within Ficus species. Hence, for Ficus associated insect communities, evolutionary scenarios that do not involve isolated plant populations may be more realistic. Whatever the initial process leading to insect speciation, data on pollinator and parasite communities, have evidenced geographically structured patterns of insect species replacement, within a context of continuous Ficus populations [8, 38, 41]. We favour a scenario in which the fig host was never geographically isolated but developed geographically structured morphological variation involving a thicker wall fruit. This did not pose a challenge to the fig entering pollinator as evidenced by the lack of spatial genetic structure of Valisia across continental sites. But only one of the parasitic wasp species followed suite and morphologically differentiated to adapt to the thicker wall of the fig in the north. A process which may have been facilitated by assortative mating, as female wasps born in thick walled figs can only mate with males borne in the same figs, i.e. by offspring of female wasps having long ovipositors.

Previous analysis of $F$. hirta has indicated that the fig lacks genetic population structuring across our study area in continental China (Additional file 1: Figure S4) [9]. Therefore, morphological variation in fig wall thickness could be due to a phenotypic response to local conditions without genetic variation. Alternatively the variation could be adaptive and genetically based. Variation in fig size may have been selected for a series of reasons other than protection against parasitism. For instance, low temperatures increase wasp development time [42]. Large figs automatically become warmer than small ones due to the thicker boundary layer of larger objects, limiting heat dissipation. As a consequence large figs often require strong evaporation to control their temperature [42]. This physical constraint may explain the absence of large fig Ficus species in dry tropical environments [43]. In more temperate environments such as in the north-eastern part of $F$. hirta's distribution, larger figs will warm up more rapidly in the sun, and a thicker fig wall would buffer daily temperature variations, accelerating pollinator development in cool seasons. Hence larger figs and thicker fig walls could have been selected in Ficus hirta for their effect on the speed of development of pollinating wasp. In agreement with this hypothesis, in Ficus hirta, figs are larger on male plants (producing pollinating wasps and pollen in their figs) than in female plants (producing seeds in their figs) [44]. An alternative could be selection on another phenotypic trait, such as leaf size, indirectly affecting fig size due to ontogenic size correlations between different plant organs [45], although we failed to detect variation in leaf size in our herbarium samples, arguing against the ontogenic hypothesis. Finally, selection of thicker fig walls could also be due to parasitic pressure, in a coevolutionary process. Indeed, a study in the south-western zone has shown that parasites had a strong impact on pollinator wasp mortality, as they killed at least $18 \%$ of the pollinating wasp larvae [37]. Further, developing larvae located closest to the figs wall were the most exposed ones to parasitism [37]. Unraveling the relative importance of the different selective factors involved in the evolution of geographically differentiated fig wall thickness will prove challenging.

The process of diversification documented here could apply to numerous situations. Indeed within Ficus, intra-specific fig size variation is widespread and is spatially structured in at least some species [21, 22]. More generally, in many plant species, the size of some organs or structures, for instance the size of acorns [17], varies geographically and provides a series of situations in which processes analogous to the one documented here could apply.

\section{Conclusions}

Non-pollinating fig wasp diversification has been shown to result from a series of processes including i) codiversification with host plants $[6,35]$, ii) changes in ecological role within a community [35], iii) host plant shifts resulting in parasite speciation [35], and iv) diversification into parapatric species driven by adaptation to 
different ranges of variation in abiotic factors and competitive exclusion $[8,38]$. In the situation documented here, diversification is driven by a biotic trait, geographic variation in host plant morphology. Hence, at least five different mechanisms of community diversification are at work in the wasp communities associated with figs.

Our results support the general hypothesis of an important role of biotic interactions in the diversification of life [46], and, in particular, the hypothesis of an important role for host plant phenotypic variation for the associated community constituted by phytophageous insect and their parasites. Because environmental conditions vary geographically, plants may vary in kind, resulting in different regional selection pressures on insects that attack the plants to diverge ecologically. This process occurs in fig wasp communities in conjunction with a series of other diversification processes, suggesting multiple answers to the question of why so many species.

\section{Additional file}

Additional file 1: Figure S1. Neighbour joining COI phylogeny of 75 Sycoscapter individuals collected from Ficus hirta. Figure S2. Neighbour joining COI phylogeny of 70 Philotrypesis individuals collected from Ficus hirta. Figure S3. Assignation of microsatellite multilocus genotypes to cluster using STRUCTURE. Figure S4. Spatial genetic structure in Ficus hirta and its associated wasps. (PDF $252 \mathrm{~kb}$ )

\section{Abbreviations}

COI: Cytochrome c oxidase subunit I; DNA: Deoxyribonucleic acid; $F_{\text {ST: }} F-$ statistics describe the statistically expected level of heterozygosity in a population. $F_{S T}$ is the effect of subpopulations compared to the total population; He: Nei gene diversity corrected for sample size; K2P: Kimura 2parameter pairwise genetic distance; PCR: Polymerase chain reaction

\section{Acknowledgements}

We thank Steve Compton and three anonymous reviewers for constructive comments and improvements to the English language.

\section{Funding}

This work was supported by National Natural Science Foundation of China (31670395; 31630008; 31370409), and Natural Science Foundation of Guangdong Province (\$2013020012814).

\section{Availability of data and materials}

The datasets of microsatellite genotype data-Philotrypesis josephi and Sycoscapter hirticola supporting this article will be accessed via Dryad.

\section{Author's contributions \\ H.Y. designed the experiments, F.K. and H.Y. analysed the data and wrote the manuscript. D. L. worked on fig size and ovipositor length, E. W. T. worked on wasp population genetics, L. N. Z. worked on some parts of fig size and ovipositor length, and drew the figure of sample sites. All authors read and approved the final manuscript.}

Ethics approval and consent to participate

Not applicable.

Consent for publication

Not applicable.

\section{Competing interests}

The authors declare that they have no competing interests.

\section{Publisher's Note}

Springer Nature remains neutral with regard to jurisdictional claims in published maps and institutional affiliations.

\section{Author details}

'Guangdong Provincial Key Laboratory of Applied Botany, and Key Laboratory of Plant Resources Conservation and Sustainable Utilization, South China Botanical Garden, the Chinese Academy of Sciences, Guangzhou 510650, China. ${ }^{2}$ CEFE, UMR 5175, CNRS, Univ Montpellier, Univ Paul-Valéry Montpellier, EPHE, IRD, 1919 route de Mende, F-34293 Montpellier Cédex 5, France.

Received: 26 May 2017 Accepted: 14 August 2018

Published online: 04 September 2018

\section{References}

1. Price PW, Bouton CE, Gross P, McPheron BA, Thompson JN, Weis AE. Interactions among three trophic levels: influence of plants on interactions between insect herbivores and natural enemies. Ann Rev Ecol Syst. 1980;11:41-65.

2. Hembry DH, Yoder JB, Roesch GK. Coevolution and the diversification of life. Am Nat. 2014;184:425-38.

3. Althoff DM, Segraves KA, Johnson MTJ. Testing for coevolutionary diversification: linking pattern with process. Trends Ecol Evol. 2014:29:82-9.

4. Stone GN, Lohse K, Nicholls JA, Fuentes-Utrilla P, Sinclair F, Schönrogge K, et al. Reconstructing community assembly in time and space reveals enemy escape in a western Palearctic insect community. Curr Biol. 2012;22:532-7.

5. Hood GL, Forbes AA, Powell THQ, Egan SP, Hamerlinck G, Smith JJ, et al. Sequential divergence and the multiplicative origin of community diversity. P Natl Acad Sci USA. 2015;112:E5980-9.

6. Jousselin E, van Noort S, Berry V, Rasplus JY, Rønsted N, Erasmus JC, et al. One fig to bind them all: host conservatism in a fig wasp community unravelled by cospeciation analyses among pollinating and nonpollinating fig wasps. Evolution. 2008;62:1777-97.

7. Cruaud A, Ronsted N, Chantarasuwan B, Chou LS, Clement WL, Couloux A, et al. An extreme case of plant-insect co-diversification: figs and fig-pollinating wasps. Syst Biol. 2012;61:1029-47.

8. Darwell $\mathrm{CT}$, Cook JM. Cryptic diversity in a fig wasp community - functionally differentiated species are sympatric but cryptic species are allopatric. Mol Ecol. 2017;26:937-50.

9. Tian E, Nason JD, Machado CA, Zheng L, Yu H, Kjellberg F. Lack of genetic isolation by distance, similar genetic structuring but different demographic histories in a fig-pollinating wasp mutualism. Mol Ecol. 2015;24:5976-91.

10. Sutton TL, Riegler M, Cook JM. One step ahead: a parasitoid disperses farther and forms a wider geographic population than its fig wasp host. Mol Ecol. 2016:25:882-94.

11. García-Robledo C, Kuprewicz EK, Staines CL, Erwin TL, Kress WJ. Limited tolerance by insects to high temperatures across tropical elevational gradients and the implications of global warming for extinction. PNAS. 2016:19:680-5.

12. Singer MC, McBride CS. Geographic mosaics of species' association: a definition and an example driven by plant-insect phenological synchrony. Ecology. 2012;12:2658-73.

13. Koenig WD, Knops JMH, Dickinson JL, Zuckerberg B. Latitudinal decrease in acorn size in bur oak (Quercus macrocarpa) is due to environmental constraints, not avian dispersal. Botany. 2009:87:349-56.

14. Harrison RD. Figs and the diversity of tropical rainforests. Bioscience. 2005; 12:1053-64.

15. Segar ST, Pereira RAS, Compton SG, Cook JM. Convergent structure of multitrophic communities over three continents. Ecol Lett. 2013;16: 1436-45.

16. Tzeng HY, Chern-Hsiung CH, Lu FY, Bain A, Chou LS, Kjellberg F. The effect of fig wall thickness in Ficus erecta var. beecheyana on parasitism. Acta Oecol. 2014:57:38-43.

17. Berg CC, Villavicencio X. Taxonomic studies on Ficus (Moraceae) in the West Indies, extra-Amazonian Brazil and Bolivia. Ilicifolia. 2004:4:5.

18. Rafidison VM, Rabevohitra R, Aumeeruddy-Thomas Y, Hossaert-McKey M, Rasplus JY, Kjellberg F. Notes taxonomiques et identification des Ficus malgaches. Acta Botanica Gallica. 2011;158:453-72. 
19. Nair PB, Abdurahiman UC, Joseph M. Two new torymidae (hymenoptera, chalcidoidea) from Ficus hirta. Orient Insects. 1981;15:433-42.

20. Conchou L, Ciminera M, Hossaert-McKey M, Kjellberg F. The non-pollinating fig wasps associated with Ficus guianensis: community structure and impact of the large species on the fig/pollinator mutualism. Acta Oecol. 2014;57:28-37.

21. Zeileis A, Hothorn T. (2002). Diagnostic checking in regression relationships. R news. 2002;2:7-10. URL https://CRAN.R-project.org/doc/Rnews/. Accessed 28 Sept 2017.

22. Zhou MJ, Xiao JH, Bian SN, Li YW, Niu LM, Hu HY, et al. Molecular approaches identify known species, reveal cryptic species and verify host specificity of Chinese Philotrypesis (Hymenoptera: Pteromalidae). Mol Ecol Resour. 2012;12:598-606.

23. Zhou MJ, Xiao JH, Bian SN, Li YW, Niu LM, Hu HY, et al. Corrigendum. Molecular approaches identify known species, reveal cryptic species and verify host specificity of Chinese Philotrypesis (Hymenoptera: Pteromalidae). Molecular Ecology Resour. 2013;13:344-6.

24. Kimura M. A simple method for estimating evolutionary rates of base substitutions through comparative studies of nucleotide sequences. J Mol Evol. 1980;16:111-20.

25. Yu H, Nason JD. Nuclear and chloroplast DNA phylogeography of Ficus hirta: obligate pollination mutualism and constraints on range expansion in response to climate change. New Phytol. 2013;197:348-51.

26. Hebert PDN, Cywinska A, Shelley LB, deWaard JR. Biological identifications through DNA barcodes. Proc R Soc B-Biol Sci. 2003;270:313-21.

27. Tamura K, Stecher G, Peterson D, Filipski A, Kumar S. MEGA6: molecular evolutionary genetics analysis version 6.0. Mol Biol Evol. 2013;30:2725-9.

28. Pritchard JK, Stephens M, Donnelly P. 2000. Inference of population structure using multilocus genotype data. Genetics. 2000;155:945-59.

29. Earl DA. vonHoldt BM. STRUCTURE HARVESTER: a website and program for visualizing STRUCTURE output and implementing the Evanno method. Conservation Genet Resour. 2012;4:359-61.

30. Hardy OJ, Vekemans X. SPAGeDi: a versatile computer program to analyse spatial genetic structure at the individual or population levels. Mol Ecol Notes. 2002;2:618-20.

31. Abellò P, Ai WM, Altmann C, Bernardi G, Bonato O, Burchhardt KM, et al Permanent Genetic Resources added to Molecular Ecology Resources Database 1 April 2012-31 May 2012. Mol Ecol Res. 2012;12:972-4.

32. Ahanchédé A, Alfaya JEF, Andersen LW, Azam D, Bautista MAM, Besnard AL, et al. Permanent Genetic Resources added to Molecular Ecology Resources Database 1 August 2012-30 September 2012. Mol Ecol Res. 2013;13. 158-9.

33. Evanno G, Regnaut S. Goudet J (2005) detecting the number of clusters of individuals using the software STRUCTURE: a simulation study. Mol Ecol. 2005; 14:2611-20

34. Nei M. Estimation of average heterozygosity and genetic distance for smal number of individuals. Genetics. 1978;89:583-90.

35. Weiblen GD, Bush GL. Speciation in fig pollinators and parasites. Mol Ecol. 2002;11:1573-8.

36. Al-Beidh S, Dunn DW, Power SA, Cook JM. Parasites and mutualism function: measuring enemy-free space in a fig - pollinator symbiosis. Oikos. 2012;121:1833-9.

37. Yu H, Compton SG. Moving your sons to safety: galls containing male fig wasps expand into the Centre of figs, away from enemies. PLoS One. 2012;7:e30833.

38. Darwell CT, al-Beidh S, Cook JM. Molecular species delimitation of a symbiotic fig-pollinating wasp species complex reveals extreme deviation from reciprocal partner specificity. BMC Evol Biol. 2014;14:189.

39. Berg CC, Pattharahirantricin N, Chantarasuwan B. Moraceae. In: Santisuk T, Larsen K, editors. Flora of Thailand. Bangkok: The Forest Herbarium, Department of National Parks, Wildlife and Plant Conservations; 2011. p. 475-675.

40. Bain A, Borges RM, Chevallier MH, Vignes H, Kobmoo N, Peng YQ, Cruaud A, Rasplus JY, Kjellberg F, Hossaert-McKey M. Geographic structuring into vicariant species-pairs in a wide-ranging, high-dispersal plant-insect mutualism: the case of Ficus racemose and its pollinating wasps. Evol Ecol. 2016;30:663-84

41. Liu M, Compton SG, Peng F-E, Zhang J, Chen X-Y. Movements of genes between populations: are pollinators more effective at transferring their own or plant genetic markers? Proc R Soc B. 2015;282:20150290.

42. Patino S, Herre EA, Tyree MT. Physiological determinants of Ficus fruit temperature and implications for survival of pollinator wasp species: comparative physiology through an energy budget approach. Oecologia. 1994;100:13-20
43. McLeish MJ, van Noort S, Tolley KA. African parasitoid fig 553 wasp diversification is a function of Ficus species ranges. Mol Phylogenet Evol. 2010;57:122-34

44. Yu H, Zhao NX, Chen YZ, Deng Y, Yao JY, Ye HG. Phenology and reproductive strategy of a common fig in Guangzhou. Bot Stud. 2006;47: 435-41.

45. Brouat C, Gibernau M, Amsellem L, McKey D. Corner's rules revisited: ontogenetic and interspecific patterns in leaf-stem allometry. New Phytol. 1998;139:459-70.

46. Mittelbach GG, Schemske DW, Cornell HV, Allen AP, Brown JM, Bush MB, et al. Evolution and the latitudinal diversity gradient: speciation, extinction and biogeography. Ecol Lett. 2007;10:315-31.
Ready to submit your research? Choose BMC and benefit from:

- fast, convenient online submission

- thorough peer review by experienced researchers in your field

- rapid publication on acceptance

- support for research data, including large and complex data types

- gold Open Access which fosters wider collaboration and increased citations

- maximum visibility for your research: over $100 \mathrm{M}$ website views per year

At $\mathrm{BMC}$, research is always in progress.

Learn more biomedcentral.com/submissions 